\section{Medos e riscos \\ contemporâneos}

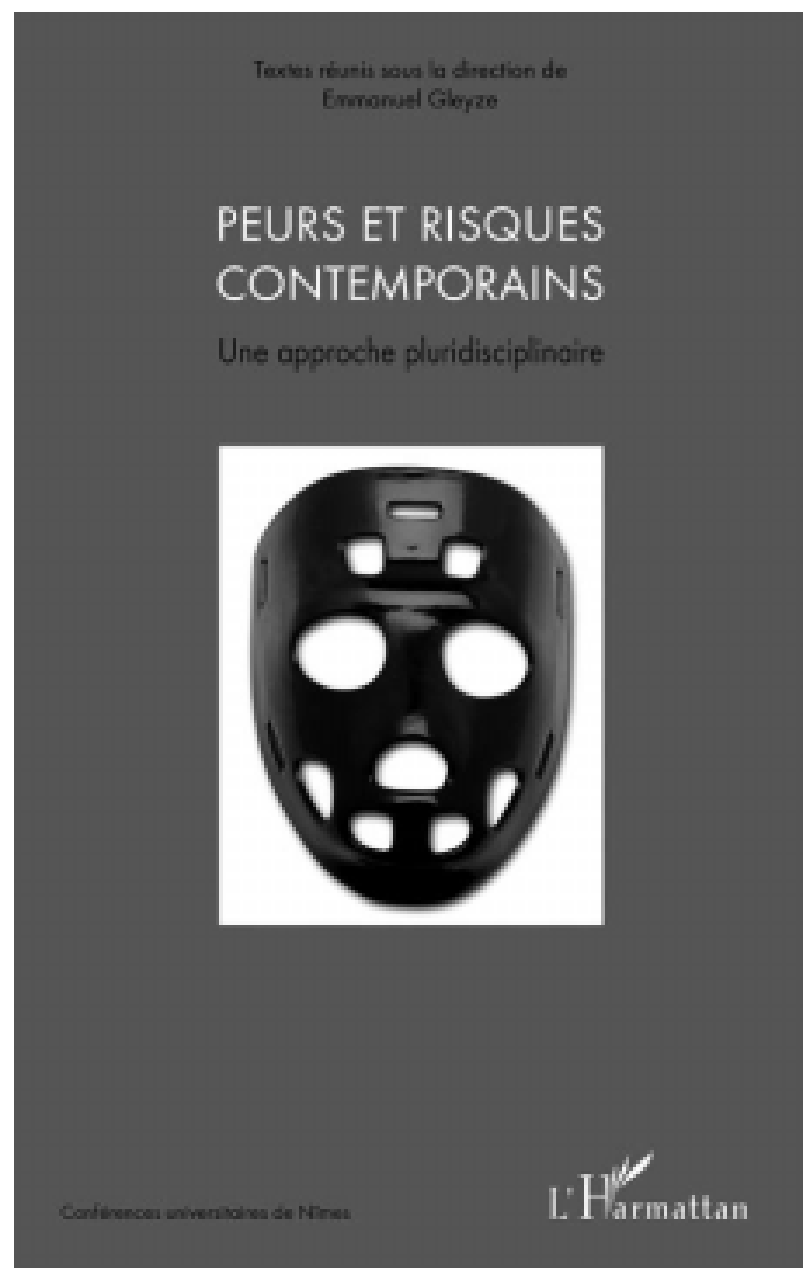

Emmanuel Gouabault

Doutorando em Sociologia/UPV - Montpellier III
ESTA COLETÂNEA DE TEXTOS aborda, com grande pertinência e atualidade, os medos em relação aos espaços públicos, às lendas urbanas, à "vaca louca", aos riscos que o desenvolvimento da biotecnologia impõem à humanidade de amanhã. Os textos foram recolhidos, principalmente, de conferências públicas ministradas no Centro Universitário de Formação e de Pesquisa de Nîmes, organizadas pela associação Encontros Universitários de Vauban.

Na introdução, "Riscos, medos coletivos e sociedade", Emmanuel Gleyze esboça um panorama global e atual de noções e definições, sob diferentes perspectivas disciplinares, de medos e riscos, o que permite a análise e a compreensão das diferentes abordagens que integram as oito contribuições da obra. Coloca-se então de imediato dentro de uma perspectiva pluridisciplinar, já que as análises que constituem o livro vão da história à sociologia e à antropologia, passando pela bioquímica, pela hidrologia e pela psicanálise. O empenho está à altura do desafio lançado ao século XXI tal como este é lembrado por Edgar Morin, em seu livro Relier les connaissances. Le défi du XXI siècle (Paris: Seuil, 1999).

A primeira parte da coletânea é consagrada aos medos apresentados na introdução sob diferentes formas e centrados sobre o medo fundamental, que é aquele da morte: o pavor. $\mathrm{O}$ pânico constitui-se então como uma variante. Trata-se de um fenômeno caracterizado geralmente por seu efeito instantâneo e sua influência sobre um pequeno número de indivíduos. Ele é compreendido através de um processo de desintegração da massa e de medo extremo, enquanto o medo, em si, é entendido como algo que permite um certo grau de intelectualização e mesmo de denegação. É também preciso levar em conta os medos coletivos, que requerem uma compreensão mais elaborada. Finalmente, o autor sublinha com pertinência esta constante em todo 
fenômeno do medo: sua originalidade, uma experiência sempre manifesta no atual.

Marylène Lieber, doutora em sociologia, ilustra esta temática no seu artigo Les peurs dans l'espace public: l'apport d'une réflexion sur le genre et les violences. Ela denuncia e desconstrói a naturalização desta forma de discriminação sexual, que aumenta o sentimento de insegurança sentido pelas mulheres no espaço público. A evidência de um risco maior de agressão para as mulheres é aqui analisada em termos de elaboração de representações sociais ligadas ao gênero. A autora nos revela, desta forma, a existência de um controle social informal predominante na utilização do espaço público pelas mulheres, que também participam da "produção-reprodução das idéias sexuais". Esta análise de gênero sobre o medo das mulheres coloca assim em evidência a construção social deste "medo profundo", que elas carregam e consideram como normal, sem perceber - ou poder reconhecer - o caráter eminentemente estereotipado e social. Marylène Lieber não esquece de sublinhar o papel do homem na manutenção dessas idéias, já que ele vê a si próprio como protetor da mulher vulnerável.

Madeleine Gueydan, psicanalista e psicóloga clínica, denuncia em seu artigo Fragilidade feminina, fragilidade maternal no século XXI: influência sobre as crianças nossa atual desumanização. Ela sublinha a necessidade de manter-se uma Humanidade unificando os processos racionais, pulsionais e arcaicos, exprimidos através das idéias de "amar, odiar e desejar conhecer". Essas três correntes são analisadas em relação às crianças, às mulheres e às mães, grupos que manifestam um contato mais forte com esta "fragilidade". A autora detém-se particularmente sobre o mal-estar que ela percebe na relação entre a futura mãe e a criança - a " maternidade" -, sintoma do recalcamento de nossos processos originários, encorajado pela sociedade. Assim Madeleine Gueydan enfatiza a necessidade de uma conscientização, tanto da coletividade como de cada um, a respeito desta parte sombria, que é a aceitação da perda, da falta de controle, da angústia, ou seja, desta fragilidade que exprime a dimensão feminoïde, presente também nos homens.

Jean-Bruno Renard, professor de sociologia, trata, no seu artigo Rumores e lendas contemporâneas, dos fenômenos de medo coletivo. Ele examina quatro temas principais concernentes às sociedades contemporâneas, ilustrando cada um com um exemplo: os perigos das novas tecnologias, o medo da violência urbana, o receio de uma natureza selvagem e o medo do desconhecido. O pesquisador expõe as diversas terminologias utilizadas neste campo de pesquisa. Depois de determinar as quatro características que definem o rumor (instabilidade, implicação, negatividade, atribuição), JeanBruno Renard propõe uma grade analítica de seis pontos, a qual permite o estudo destes objetos. A prática de uma hermenêutica destes textos deve ser sublinhada, já que a análise aprofundada empreendida pelo pesquisador permite colocar em evidência uma "modernização dos motivos imemoriais pertencentes ao patrimônio do folclore narrativo da humanidade".

Emmanuel Gleyze apresenta, na segunda parte de sua introdução, as noções de risco através de uma tipologia de três categorias. A primeira interroga os riscos valorizados negativamente: riscos naturais, alimentares, sanitários, tecnológicos, de conflitos armados e étnicos. A segunda chama nossa atenção à existência de riscos valorizados positivamente, que correspondem a um certo gosto pelo risco. A terceira participa da primeira, oferecendo um recuo globalizante, já que ela permite a certos pesquisadores, como F. Ewald, a realização de uma leitura da evolução da sociedade.

O primeiro pesquisador a ilustrar a temática dos riscos é o hidrólogo Michel Desbordes, em seu artigo intitulado O risco pluvial no Languedoc-Roussillon: a memória esquecida. Com a intenção de lutar contra o esquecimento da existência de "acasos climáticos" (risco pluvial), característicos do Languedoc-Roussillon, o autor perse- 
gue as ilusões de toda crença em um desenvolvimento urbano que não leve em conta a necessidade de um princípio de precaução contra esses acasos. Ele mostranos a importância de dirigirmo-nos rumo a um desenvolvimento durável, através do caso de Nîmes, que deveria ter levado em conta a "vulnerabilidade" dos espaços, agravada pelo desenvolvimento de sua ocupação. O risco de inundações de um setor geográfico dado, e particularmente no Languedoc-Roussillon, como lembram, a cada ano, as reportagens dramáticas, resulta, dessa forma, da associação de acasos climáticos específicos com a vulnerabilidade do setor.

Sylvain Lehmann, bioquímico, explora os riscos alimentares e sanitários no artigo, intitulado com humor, Rezemos pelas vacas loucas. Sua análise se concentra sobre as doenças de zigotos, agentes patogênicos responsáveis das encefalopatias espongiformes transmissíveis. Através dos exemplos da febre do carneiro e da doença da "vaca louca", o pesquisador nos apresenta o conhecimento atual destas enfermidades: de suas origens possíveis entre os homens às dificuldades de tratamento, passando pela sua transmissão do animal ao homem. Sylvain Lehmann insiste finalmente sobre a necessidade de estudos mais aprofundados sobre estas doenças, tanto pelo benefício da saúde pública quanto pelo avanço dos conhecimentos científicos.

Gabriel Jandot, historiador, apresenta uma análise de outro tipo de risco, que se apóia sobre $A$ previsibilidade dos conflitos internacionais. $\mathrm{O}$ autor procura estabelecer uma grade de leitura de situações referente a crises internacionais beligerantes. Este diagnóstico se baseia principalmente sobre uma análise histórica, mas também sobre uma análise plurifatorial de parâmetros ativos (aspectos geo-sociais e espaciais, forças presentes, vontades expansionistas), dependentes (tensões, imagens mentais) e externas (potencialidade de alianças, de intervenções) em um espaço nacional onde as fronteiras são concebidas como estáticas ou expansionistas. Este ensaio é enriquecido pela elaboração detalhada de dois esquemas temporais sobre a evolução das situações de crise, bem como de várias tipologias matizando a intensidade dos diferentes parâmetros.

Ilustrando o risco valorizado positivamente, Yan Bour, doutorando em antropologia, trata do estrangulamento, em um artigo intitulado $O$ estrangulamento lúdico: riscos e medos atuais de uma prática corporal imemorial. O pesquisador, escolhendo uma abordagem da antropologia social e cultural, ilustra seu propósito enfocando o jogo do lenço. Ele sublinha uma dimensão midiática, mas, sobretudo, analisa as lógicas e modalidades desta prática atual. Yan Bour define as três formas deste jogo secreto: a transgressão pontual dos limites ("jogo de iniciação" e rito de passagem); curvar-se prolongadamente sobre si mesmo ("jogo íntimo"); e a regular prática auto-erótica ("jogo auto-erótico"). Dessa forma, a análise questiona a pluralidade de causas destas práticas, colocando em dia as implicações psicológicas do adolescente, o contexto sociocultural e a perenidade do jogo auto-erótico através da história.

$\mathrm{O}$ artigo do filósofo Paul-Antoine Miquel, Le principe de constructible constructibilité en philosophie politique, encerra essa rica abordagem sobre os riscos, enfatizando particularmente os riscos tecnológicos. Com efeito, o filósofo desenvolve a idéia de que a relação étnica entre o indivíduo e si próprio é hoje totalmente dependente de um ambiente tecnológico que a sobredetermina. Esse ponto de vista é desenvolvido especialmente através da noção de biopoder de Foucault e dos riscos atuais, mas, sobretudo, futuros, do eugenismo estatal ou liberal. A perspectiva do autor é, entretanto, mais global ainda, já que ele propõe uma reflexão sobre a democratização da economia. Para ele, o processo de democratização é valido, na medida em que permite o desenvolvimento de uma responsabilidade do homem para com ele e para com os outros. Finalmente, Paul-Antoine Mi- 
quel fundamenta-se sobre o princípio de "construtível construtibilidade" da humanidade, que corresponde a uma necessidade de que aquilo que hoje parece justo à humanidade não impeça a possibilidade de a humanidade de amanhã agir de acordo com o principio de justiça. O filósofo crê ser importante, então, o desenvolvimento de uma ética, e que esta seja pensada na sua relação com a política, estando o homem diante de crescentes possibilidades de construir-se - e de destruir-se - a partir do desenvolvimento da tecnologia.

Para concluir, Medos e riscos contemporâneos: uma aproximação pluridisciplinar, mantém os objetivos anunciados no título. A originalidade das reflexões e das perspectivas de pesquisa propostas são realmente estimulantes, além de o texto oferecer ao leitor abordagens complementares (por exemplo, os dois primeiros artigos tratam da mulher contemporânea). É certo que poderíamos desejar ver analisados outros objetos, como a internet ou o medo do ponto de vista da etnologia, mas esta coletânea constitui-se, pela sua diversidade, como um conjunto suficientemente coerente para satisfazer ao leitor, iniciado ou não, a estes objetos e a estes caminhos .

\section{Nota}

GLEYZE, Emmanuel (Org.). Peurs et Risques contemporains. Une approche pluridisciplinaire. Paris: L'Harmattan, Col. Conférences universitaires de Nîmes, 2006. 